\title{
Prediction of Fracture Pressure in Niger Delta Deep Offshore
}

\author{
Kehinde E. Ajayi, Azubuike H. Amadi, Victor D. Ola, Raphael E. Obonin, and Nnaemeka Achara
}

\begin{abstract}
During drilling operations, it is essential to keep the wellbore pressure within the maximum value of the fracture pressure and minimum value of the pore pressure of the formation. To handle this challenge, the fracture pressure of the formation must be known as it is significant to determining the mud window design. This study developed a correlation that could predict the formation fracture pressure in the Niger Delta deep offshore field. Two different fields were considered for this model named Field 1 and 2. From these fields, fracture pressure data were gotten from 21 wells during leak off test (LOT) at different casing shoe depths. While carrying-out the analysis of data, assumptions were made that the formations throughout the Niger Delta basin obeys the principle of horizontality. Also, that the fracture pressure at same depth is uniform with the pressure at other location in the Delta. Scatter plot was used as the tool for the data analysis. A line of best fit was drawn to arrive at the correlation. This correlation has an $\mathbf{R}^{2}$ coefficient values of 0.9969. In conclusion, the correlation gotten from this study for predicting fracture pressure has shown to align with some data sets from the Niger Delta fields with very little variation. This can be used for planning of further drilling operations in the Niger Delta to make it easier, faster and more economical.
\end{abstract}

Index Terms - Fracture Pressure, Equivalent Mud Weight, LOT, Correlation, Niger Delta.

\section{INTRODUCTION}

Over the years, majority of exploration has been carried out in onshore and shallow offshore locations but changing economics and the depletion of the resource in shallow offshore has initiated the push for exploration to Deepwater and ultra-Deepwater locations. As a result of this, drilling in Deepwater is on the increase than ever before but little is known about its geo-pressures; overburden, pore and fracturation pressures. The knowledge of these pressure parameters is needed in achieving optimum well design, drilling operations, casing design, stimulation treatments and economical well planning. However, one of the major challenges is estimating the right fracture gradient as this is

Published on February 4, 2021

K. E. Ajayi, Institute of Petroleum Studies, University of Portharcourt, Nigeria.

(e-mail: ajayikehindeelijah@gmail.com).

A. H. Amadi, World Bank Africa Center of Excellence in Oilfield Chemical Research, University of Portharcourt, Nigeria.

(e-mail: azubuikehopeamadi@gmail.com).

V. D. Ola, Institute of Petroleum Studies, University of Portharcourt, Nigeria.

(e-mail: olavictord@gmail.com).

R. E. Obonin, Institute of Petroleum Studies, University of Portharcourt, Nigeria.

(e-mail: Etorobonin ${ }^{\circledR}$ gmail.com).

N. Achara, Accrete Petroleum Limited, Nigeria.

(e-mail: acharannaemeka@gmail.com). an essential criterion for mud weight design in both the preliminary phase of drilling planning and whilst drilling operation is ongoing. When the mud weight is greater than the fracture gradient of the formation, the well bore experiences stress failure, causing losses of drilling mud due to lost circulation. Furthermore, it is good to note at this point that fracture gradient is the relationship between formation fracture pressure with respect to depth. So, what is fracture pressure? It is the pressure required to fracture the formation and cause mud loss from the wellbore into the induced fracture [1]. In practice, fracture pressure is measured from leak-off tests (LOT). Although many correlations exist for the estimation of fracture pressure gradient, they are however mostly limited to onshore or shallow water wells. There is therefore the need to develop correlations that can yield improved prediction of fracture pressure for deep water wells so we can have more knowledge and control of the prediction process, as a more accurate geo-pressure prediction can lower cost, reduce problems and improve the safety of drilling operations generally.

As more exploration activities is being carried out in Deepwater locations, it is expected to know the fracture pressure gradient of the formation to drill in other to prevent lost circulation as a result of wrong selection of mud weight and to avoid fracturing of the formation. A Leak-Off Test is a common and efficient method used for evaluating fracture pressure gradient, but costly and time consuming to carry out also having the limitation that on several points of a drilled formation, it cannot be used. Hence several theoretical and correlation models have been developed and modified to estimate fracture pressure but are mostly for land and shallow waters. Therefore, this paper is presented to predict the fracture pressure in Niger Delta Deep offshore locations.

To achieve this aim, the objectives of the study are to:

1) Identify existing correlations used for predicting fracture pressure and their modifications.

2) Generate a new correlation that can help in the future predictions of fracture pressure.

The prediction of fracture pressure in deep offshore Niger Delta is as important as predicting formation pressure in well planning. Unless fracture pressure is taken into account, expensive and troublesome problems is likely to be developed during drilling operations. As concentration over the years has been on onshore and shallow offshore, this study is significant in adding to the limited research work done in predicting fracture pressure in deep offshore.

For the purpose of this study, we would be looking at how we can use the Leak-Off Pressure approach to develop the fracture pressure in Deepwater fields with also the 
considerations of other stress factors (e.g., overburden) on the formation and making correlation out of it using excel spreadsheet. A couple of deep offshore fields will be considered on the basis of the Leak-Off Test (LOT) performed on some wells. The study considered are fields located in the Niger Delta Basin formation of the Niger Delta region.

\section{FORMATION PORE PRESSURE}

Pore pressure which is referred to as formation pressure is the pressure within the reservoir pore spaces. It is comparable to the hydraulic potential measured at depth with respect to earth's surface. Likewise assumed to be uniform in a small volume of interconnected pores [1] but it can vary from normal to abnormal pore pressures. If the pore pressure is lower or higher than the hydrostatic pressure (Normal Pore Pressure), it is referred to as an abnormal pore pressure. Overpressures particularly, can greatly increase drilling down time and cause serious drilling incidents. If the prediction of the abnormal pressures in the formation is not accurate before drilling the well, the safety of the drilling operations will be jeopardized leading to blow outs, pressure kicks and fluid influx [2]. So, Drillers try to counter balance this formation pressure by using drilling fluids of higher mud density to keep this pressure gradient within the mud window, consequently, inducing a pressure that is equal to the formation pore pressure at the well base which is approximately the same as formation pore pressure. It is one of the most essential considerations for well planning, drilling operation and geological analysis.

\section{OVERBURDEN PRESSURE}

Overburden pressure is that vertical stress imposed by the overlying formation at a point of reference beneath the surface. These overlying layers can include rock columns and bodies of water. In other words, it is the exerted hydrostatic pressure by all the material above that point of reference. The density of the combined weight is referred to as the bulk density $\left(\rho_{\mathrm{d}}\right)$. In an area under consideration, the overburden gradient is not constant with depth due to disparity in lithology and pore fluid densities. Also, the degree of compaction and formation density is directly proportional to the overburden i.e., overburden increases as degree of compaction and formation density increases. Why is it significant? Because we will use it to work out the rock fracture pressure.

\section{FRACTURE PRESSURE}

Fracture pressure is the pressure at which fracture will occur in the formation. Hence, it induces fracture causing tensile failure and losses of drilling fluid from the wellbore. The fracture pressure with respect to depth gives the fracture gradient as shown in Fig. 1. This is a crucial parameter for both well planning and drilling operation. There are several approaches to determine fracture gradient which could be theoretical and empirical or experimental.

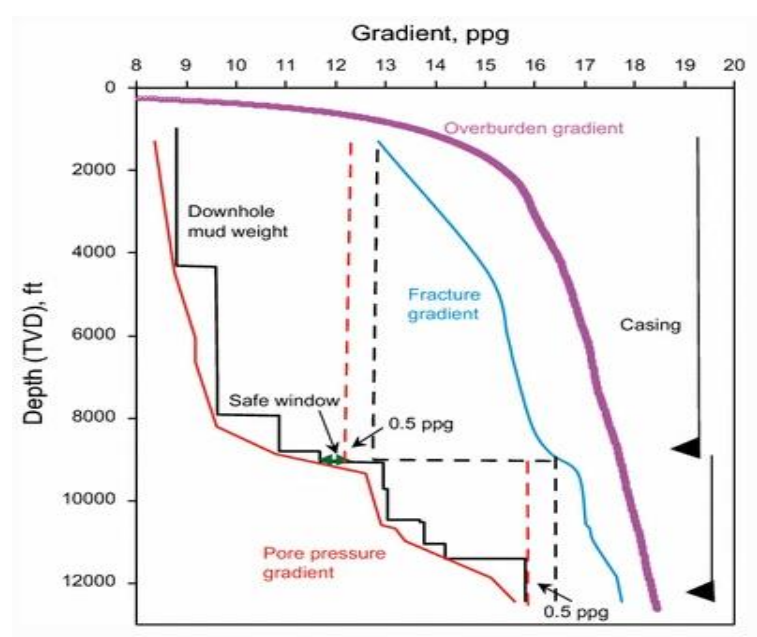

Fig. 1. Plot of Pressure Gradient Against Depth [13].

\section{HubBERT AND WILlis CORRELATION AND ITS MODIFICATION}

\section{1) Hubbert And Willis Correlation}

In 1957, Hubbert and Willis proposed a correlation assuming that the minimum stress is equal to the minimum injection pressure to open, hold and extent a fracture. This was probably the first correlation for calculating fracture gradient and it has been worked on over the years.

$$
\begin{aligned}
& F_{i n j}^{\min }=\sigma_{h}^{\prime}+\mathrm{p} \\
& F_{i n j}^{\min }=\sigma_{h}
\end{aligned}
$$

where:

$F_{i n j}^{\min }=$ Minimum Injection Pressure.

$\sigma_{h}^{\prime}=$ Effective Minimum Stress.

$\sigma_{h}=$ Minimum Stress.

$\mathrm{p}=$ Pore Pressure.

Hubbert and Willis went a step further and assumed that the effective minimum stress is horizontal under the conditions of a growing normal fault and has approximately a half to one-third value of the effective overburden stress:

$\sigma_{h}^{\prime}=\left(\sigma_{h}-p\right) / 3$

Therefore, the minimum fracture pressure can also be expressed as:

$$
F_{i n j}^{\min }=\frac{1}{3}\left(\sigma_{v}-p\right)+\mathrm{p}
$$

Or

$$
F_{i n j}^{\min }=\frac{1}{2}\left(1+\frac{2 P}{D}\right)
$$

$\sigma_{v}=$ vertical stress

$\frac{P}{D}=$ pore pressure gradient, $\mathrm{psi} / \mathrm{ft}$.

While the maximum fracture pressure:

$F_{i n j}^{\max }=\frac{1}{2}\left(1+\frac{P}{D}\right)$

Equation (1) and (2) is premised on the supposition that 
the overburden pressure gradient is approximately 1 psi per foot. Hubbert and Willis are not widely utilized, due to the low values it normally yields because of the assumption of a constant stress ratio of $1 / 3$ to $1 / 2$ of the vertical stress. [3].

\section{B. Ben Eaton Correlation}

Eaton found that the Hubbert and Willis correlation was not efficient, so he modified it by introducing the Poisson's ratio which give the expression fracture gradient as:

$$
\mathrm{FP}=\frac{v}{1-v}(\mathrm{Gob}-\mathrm{Gpp})+\mathrm{Gpp}
$$

FP = Fracture gradient

Gob $=$ Overburden gradient $(\mathrm{psi} / \mathrm{ft})$.

$\mathrm{Gpp}=$ pore pressure gradient $(\mathrm{psi} / \mathrm{ft})$.

$\mathrm{V}=$ Poisson's ratio.

According to Eaton, the above expression is applicable as long as the following steps are considered:

- Estimate the specific Poisson's ratio of the area

- Determine the specific overburden stress gradient of the area

- For the well under consideration, use an accurate pore pressure prediction [4].

However, in 1988 Constant and Bourgoyne went further to predict fracture pressure for deepwater using Eaton's correlation by exponentially fitting effective stress ratio to depth for formations in the US Gulf Coast [5]

$$
\mathrm{FP}=\left[1-\mathrm{A} e^{(B * D)}\right][\sigma \mathrm{v}-\mathrm{PP}]+\mathrm{PP}
$$

Hence, using uniaxial strain model concept, Avasthi and some other scholars worked on Eaton's fracture pressure correlation by introducing Biot's poro-elastic constant [6].

$$
\mathrm{FP}=\left[\frac{V}{1-V}\right][\sigma \mathrm{v}-\alpha \mathrm{PP}]+\alpha \mathrm{PP}
$$

However, to modify Avasthi's correlation on the principle of Hooke's law with coupling pore pressure and stresses, [7] Zhang and Zhang (2017) included minimum stress coefficient and is expressed as:

$$
\mathrm{FP}=\left[\frac{V}{1-V}\right][\sigma \mathrm{v}-\alpha \mathrm{PP}]+\alpha \mathrm{PP}+\left[\frac{c}{1-v}\right] \sigma \mathrm{v}
$$

\section{MATTHEW AND Kelly METHOD}

To represent formation properties which is a monotonic function of depth, [8] used an empirical "matrix stress coefficient". This is similar to Hubert and Willis but the concept of a variable horizontal to vertical stress ratio was introduced. Using Matthews and Kelly method to estimate the fracture gradient, the following steps were listed to be followed:

- Obtain the pore pressure in the formation.

- Determine the effective stress, $\sigma=1.0 \mathrm{D}-\mathrm{p}$.

- Determine the depth Di for which the matrix stress $\sigma$ would be the normal value:

$\mathrm{Di}=\frac{\sigma}{0.535}$
- Use the value of Di from the preceding step with Fig. 3 to determine K.

- Calculate the fracture gradient with the resulting data using the Matthews and Kelly fracture gradient equation, which follows:

$$
\frac{P w}{D}=\mathrm{Ki}\left(\frac{\sigma}{D}\right)+\frac{p}{D}
$$

- Make a Plot of fracture gradient against depth.

Matthew and Kelly have made it clear the effect of depth and formation pressure on fracture pressure. However, the limitation of this model is the assumption of overburden stress being equal to $1.0 \mathrm{psi} / \mathrm{ft}$ of depth and assuming that stress ratio in deepest normally pressured formation is equal to that of abnormally pressured formation in estimating fracture gradient. As a result of need for improvement, Goldsmith and Wilson used least-square curve fitting to develop empirical equations to predict fracture gradient for a localized area. Although the equations are tedious to apply but it is an advancement to Matthew and Kelly model [4]. The Leak off Test (LOT) which is a very important test done to ascertain the Leak Off Pressure (LOP) of a formation is represented in Fig. 2 below.

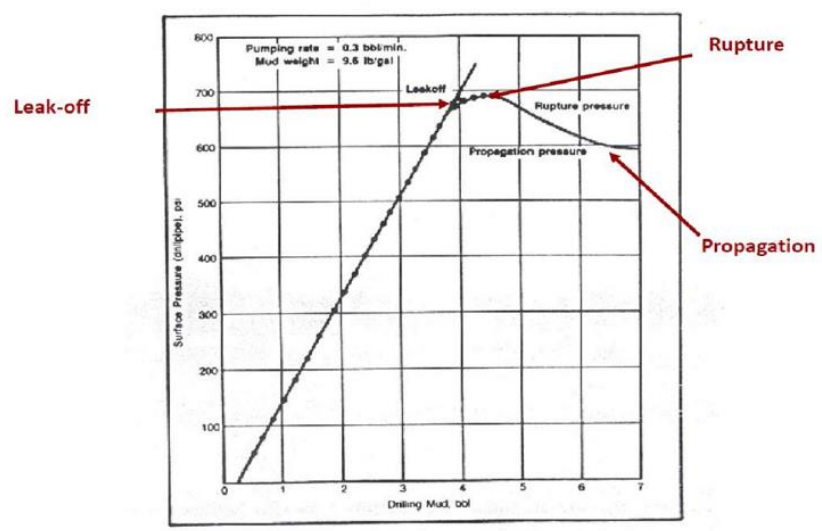

Fig. 2. Graphical Representation of a Leak Off Pressure (LOP) [14].

\section{EXISTING CORRELATIONS FOR NIGER DELTA}

\section{1) Oton Correlations}

In 1980, Oton developed two correlations for fracture gradient of which one was for shallower continental sediments and the other was for underlying marine sediments. He made mathematical expression for both sediment environment as this:

$$
\frac{F}{D}=\frac{P}{D} \frac{1}{2} \frac{\sigma_{V}}{D}
$$

For the shallower sediments, and

$$
\frac{F}{D}=\frac{F}{D}+\frac{1}{1.5} \frac{\sigma_{V}}{D}
$$

For the underlying sediments.

assuming a constant Poisson ratio of 0.4 for marine sediments and 0.333 for continental sediments. This assumption will give an erroneous result at shallower and deeper depths because the range is narrow [9]. 


\section{2) Ajienka Fracture Gradient Correlation}

Ajienka et al. [10] came up with a correlation for fracture gradient using linear multiple regression. The total of one thirty-five leak off test data were used from ninety-three onshore wells ranging from $2159 \mathrm{ft}$ of depth to $13,070 \mathrm{ft}$. It was assumed that the matrix stress ratio $\mathrm{Ki}$ is depth dependent and a correlation was developed in that regard [10]. The correlation is as follows:

$$
\begin{aligned}
& \frac{F_{P}}{D}=14.57595+0.0002193 \mathrm{D}-16.16777\left(\frac{S}{D}\right)-0.270395 K_{i} \\
& 0.6665068\left(\frac{P}{D}\right)
\end{aligned}
$$

where $K_{i}=0.1357264+0.0000366 D$.

3) Reginald-Ugwuadu Fracture Pressure Prediction Model

Reginald-Ugwuadu et al. (2014) proposed a model which he assumed that the Leak-off gradient of the formation is an approximate representation of the formation strength. This prediction model for fracture pressure is commonly calibrated for the Niger Delta sediments based on the combination of LOT data obtained from onshore, swamp and shallow offshore wells [11].

$$
F P=0.000029\left(D^{2}\right)+0.46 D
$$

\section{4) Oloruntobi Fracture Pressure Correlation}

Oloruntobi et al. [12] proposed a fracture pressure correlation for an overpressure environment in Niger Delta by incorporating LOT measurements. The model can be applied in land, swamp and shallow offshore depth of less than $500 \mathrm{ft}$ water depth of the Niger Delta basin [12].

$$
\begin{aligned}
\mathrm{FP}_{\mathrm{NPT}} & =0.06817[\mathrm{D}]^{1.2662} \\
\mathrm{PP}_{\mathrm{n}} & =0.433[\mathrm{D}] \\
\mathrm{FP} & =0.06817[\mathrm{D}]^{1.2662}+0.6051\left[\mathrm{PP}_{\mathrm{a}}-\mathrm{PP}_{\mathrm{n}}\right]-0.0000486\left[\mathrm{PP}_{\mathrm{a}}-\right.
\end{aligned}
$$$$
\mathrm{FP}-\mathrm{FP}_{\mathrm{NPT}}=0.6051\left[\mathrm{PP}_{\mathrm{a}}-\mathrm{PP}_{\mathrm{n}}\right]-0.0000486\left[\mathrm{PP}_{\mathrm{a}}-\mathrm{PP}_{\mathrm{n}}\right]^{2}
$$

\section{METHOD OF ANALYSIS}

\section{A. Research Design}

The design method adopted for this study is the analytical method, requiring the use of tables, graphs, equations, and correlations for explanations.

\section{B. Source of Data}

The data sourced for this study is gotten from field generated data from actual wells in the deep offshore of Niger delta basin. The data came from twenty (20) wells in two fields in from a LOT.

\section{Method of Data Collection}

The data used for this study were collected from Leak Off Test (LOT) performed at different depth in wells drilled in the Niger Delta basin. Other data gotten were Leak Off Pressure and Fracture Pressure.

\section{Validity of Data}

This data is assured as validated because the wells have been drilled already and the data set was automatically extracted from the database while QA/QC was also done to ensure its correctness.

\section{E. Data Analysis}

The method used to analyze the data gotten is scatter plot. This was adopted because the data set did not follow a linear equation format. A graph of LOT equivalent density versus depth was plotted to generate a line of best fit for estimated fracture equivalent density which is subsequently used in calculating the fracture pressure. This corresponds to the correlation model that defines the data set points plotted. The degree of coherency is also determined from the $\mathrm{R}^{2}$ coefficient generated alongside the model.

The values of the calculated fracture pressure were plotted against depth to generate a correlation that only depends on depth and not equivalent density.

Fracture Pressure $(\mathrm{FP})=\left(\mathrm{LOT}^{*}\right.$ Depth $) / 10.2$

\section{F. Assumptions}

The following assumptions were made in the course of this study.

1) The Niger Delta basin respects the principle of horizontality in its geological formation.

2) The fracture pressure with respect to depth is constant throughout the formation.

\section{RESUlts AND Discussion}

The following are the plots generated from the series of LOT done on field 1 and 2 .

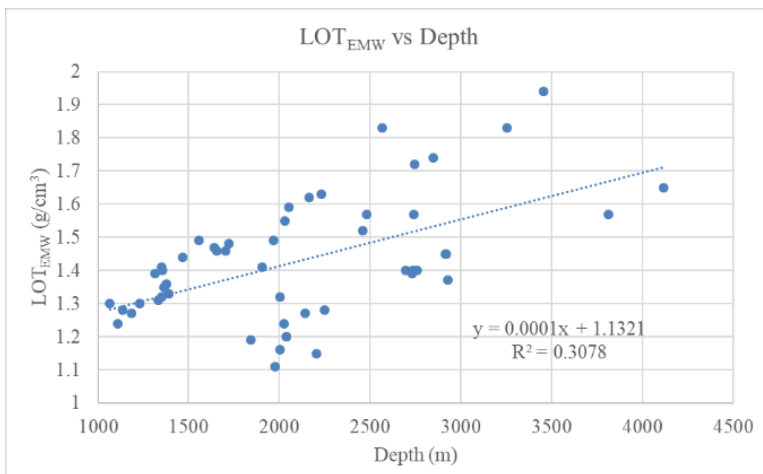

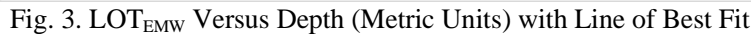

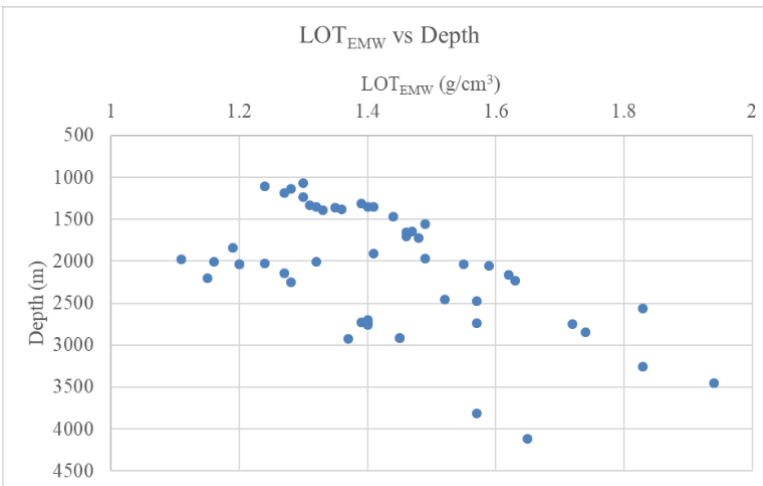

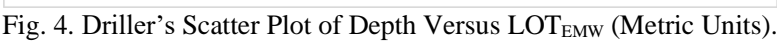




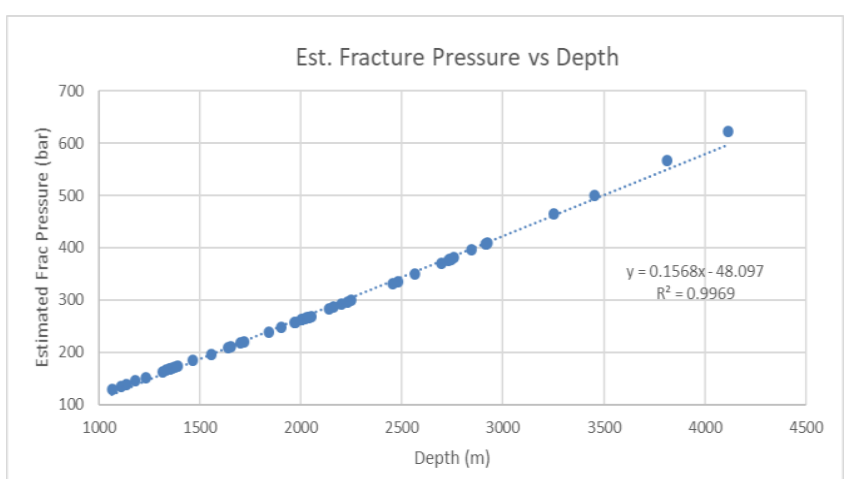

Fig. 5. Estimated Fracture Pressure Versus Depth (Metric Units) with Line of Best Fit.

From the plots generated with the data, an equation of fracture equivalent density that corresponds to the line of best fit is given in figure 3 as shown below.

$$
\mathrm{y}=0.0001(\mathrm{x})+1.1321
$$

where

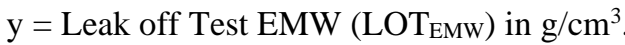

$\mathrm{x}=$ Depth $(\mathrm{Z})$ in meters.

Equation 1 can therefore be written as:

$$
\mathrm{LOT}_{\mathrm{EMW}}=0.0001(\mathrm{Z})+1.1321
$$

To develop a model for fracture pressure in metric unit (bar) we employ.

From the equation (3) we generated fracture pressure for the leak off test equivalent density. Also, we deduce an equation for fracture pressure from Equation (3) and (5) as:

Fracture Pressure $(\mathrm{FP})=([0.0001(\mathrm{Z})+1.1321] \mathrm{x} \mathrm{Z}) / 10.2$

Fracture Pressure $(\mathrm{FP})=9.8 \times 10-6\left(\mathrm{Z}^{2}\right)+0.11099(\mathrm{Z})$

From the fracture pressure-depth plot, a correlation was generated from line of best fit in Fig. 5.

$$
y=0.1568(x)+48.097
$$

where

$\mathrm{y}=$ Fracture pressure $(\mathrm{FP})$ in bar.

$\mathrm{x}=$ Depth $(\mathrm{Z})$ in meters

Equation (6) can be merged with Equation (7) and rewritten as:

$$
F P=0.1568(Z)-48.097
$$

\section{$\mathrm{Or}$}

$$
\mathrm{FP}=0.8107(\mathrm{Z})-1098.5 \text { (oilfields unit) }
$$

\section{A. Validation of Equation}

To test run this correlation equation generated, data sourced for but not used in the generation of this equation was used to run a quality assurance. Negligible deviations are seen from the correlation model and the data estimations. This is shown in Fig. 6 and 7 below using FP=
0.1568(Z) - 48.097 for metric units and FP $=0.8107(\mathrm{Z})-$ 1098.5 for oil field units as the correlation equation.

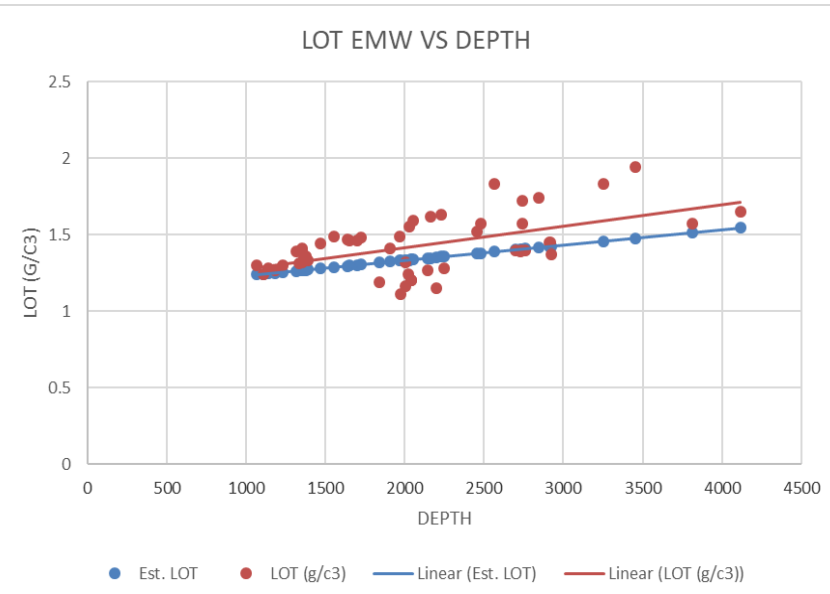

Fig. 6. Comparison chart of original $\mathrm{LOT}_{\mathrm{EMW}}$ and estimated $\mathrm{LOT}_{\mathrm{EMW}}$ against depth.

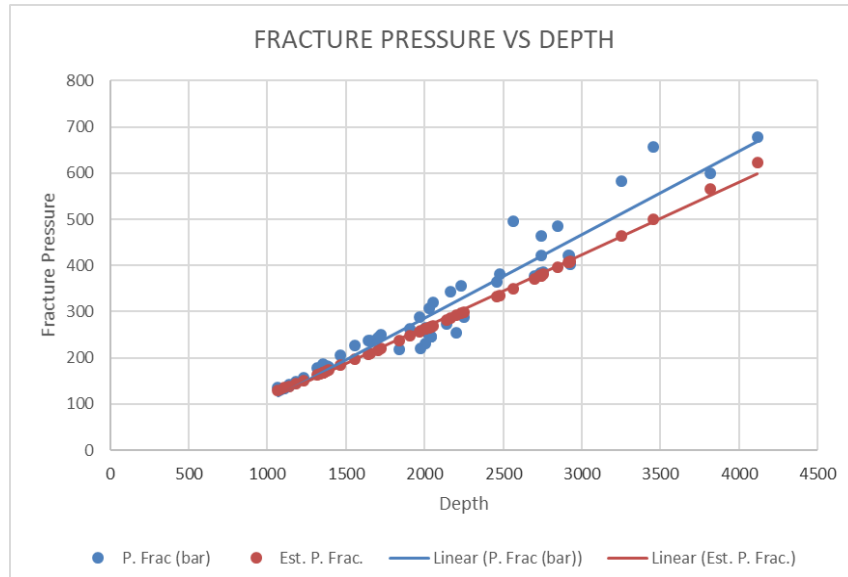

Fig. 7. Comparison chart of original LOP and estimated Fracture pressure against depth.

\section{B. Discussion of results}

As seen from the plots above, the data points followed a trend corresponding to the line of best fit. For the metric unit, the line had a $\mathrm{R}^{2}$ value of 0.9969 and 0.9944 for oilfield units. It can be observed that there was a deviation range of 5.0 to 10.0 between original field data used and the data estimations made with the use of the FP $=0.1568(\mathrm{Z})$ 48.097 equation. And deviation range of 500 to 900 when $\mathrm{FP}=0.8107(\mathrm{Z})-1098.5$ equation is used for oilfield units. This deviation is as a result of insufficient data which makes the correlation not to give true representation of the NigerDelta basin and just as stated earlier the data that was used in validating this correlation is gotten from another field. So, this disparity is inevitable unless enough data is available.

\section{CONClUSION}

Conclusively, a model to predict the formation fracture pressure in the Niger Delta deep offshore which can help in saving cost and time of leak off test was generated. It could also be seen that the model generated for predicting fracture pressure in the Niger Delta deep offshore is within the range of increase between 5 to 10 compared to the original fracture pressure gotten from the leak off test. The correlation equation derived from this analysis might not be 
fully representative of the data points for the whole of Niger Delta Basin since the data used is limited to two fields. In addition, the correlation model can be improved with more data to predict the fracture pressure in Niger Delta Offshore.

\section{RECOMMENDATIONS}

It is recommended that more data points be used to improve the model. Ensure quality data is always used so your results can be a true representation of the fracture pressure in the Niger Delta basin. Finally, it is advised that more researches should be done in this area, as a quick look could save time and cost.

\section{ACKNOWLEDGMENT}

We thank God Almighty for the insight to conclude this research. We specially thank our parents and the Institute of Petroleum Studies, University of Portharcourt, Nigeria for affording us the financial support, guidance and enabling environment.

\section{REFERENCES}

[1] Adewale, D. (2019), Lecture on Pore Pressure and Fracture Gradient Relationship [PowerPoint Slides]. Institute of Petroleum Studies, Uniport.

[2] Kankanamge, T. (2013). Pore Pressure and Fracture Pressure Modelling With-Offset Well Data and Its Application To-Surface Casing Design of a Development Well Deep Panuke Gas Pool Offshore Nova Scotia.

[3] Hubbert, M. K., \& Willis, D. G. (1957). Mechanics of Hydraulic Fracturing.

[4] Eaton, B. A. (1969). Fracture Gradient Prediction and Its Application in Oilfield Operations. Journal of Petroleum Technology, 21(10), 1353-1360. doi:10.2118/2163-pa.

[5] Constant, D. W., \& Bourgoyne Jr, A. T. (1988). Fracture-gradient prediction for offshore wells. SPE drilling engineering, 3(02), 136140.

[6] Avasthi, J. M., Goodman, H. E., \& Jansson, R. P. (2000, January). Acquisition, Calibration, and Use of the In Situ Stress Data for Oil and Gas Well Construction and Production. In SPE Rocky Mountain Regional/Low-Permeability Reservoirs Symposium and Exhibition. Society of Petroleum Engineers.

[7] Zhang, Y., \& Zhang, J. (2017). Lithology-dependent minimum horizontal stress and in-situ stress estimate. Tectonophysics, 703, 1-8.

[8] Matthews, W. R., \& Kelly J (1967). How to predict form pressure and fracture gradient from electric and sonic logs. Oil and Gas J 65:92106.

[9] Ajienka, J., Egbon, F., \& Onwuemena, U. (2009, January). Deep offshore fracture pressure prediction in the Niger Delta-A new approach. In Nigeria Annual International Conference and Exhibition. Society of Petroleum Engineers.

[10] Ajienka J, Nwokeji B (1988) Evaluating the performance of onshore fracture pressure gradient correlations in the Niger Delta. University of Port Harcourt.

[11] Reginald-Ugwuadu, O. G., Alabi, T. I., Eze, J. O., \& Ebisike, R. C. (2014, August). Fracture Gradient Estimation in the Niger Delta-A Practical and Statistical Approach. In SPE Nigeria Annual International Conference and Exhibition. Society of Petroleum Engineers.

[12] Oloruntobi, O., Falugba, O., Ekanem-Attah, O., Awa, C., \& Butt, S. (2020). The Niger Delta basin fracture pressure prediction. Environmental Earth Sciences, 79(13), 1-11.

[13] Springer (2007). Fracture gradient prediction; an overview and an improved method https://link.springer.com/article/10.1007/s12182017-0182-1.

[14] Drilling Manual (2017). Leak Off Test procedure and calculation sheet https://www.drillingmanual.com/2017/12/leak-off-testprocedures. 